\title{
Motivation for Participation in Peace Support Operations: Initial Findings among Slovenian Soldiers
}

\author{
Ljubica Jelusic*
}

\section{Introduction}

The question of why soldiers, policemen, civil servants, or members of civil society are motivated to participate in efforts dedicated to keeping, enforcing, building, or making peace is old as the peacekeeping efforts of the global community, and at least conditionally connected with the phenomenon of "willingness to fight" in classical military operations. The term "willing to fight" should be, within the scope of peace endeavors, redefined into "willing to pacify, but without fighting" because, in the majority of peace operations that have taken place after the Second World War, the given mandates were very limited in terms of allowing the use of weapons. In most cases, participants had light armament, if any. ${ }^{1}$

If morale, motivation, and cohesion are the core concepts that guide the actions of military combatants, can we use them to explain the behavior of the peacekeepers (the same soldiers in both cases) as well? The dilemma derives from the tendency to understand soldiers as schizophrenic employees, who have to possess highly-tuned combat readiness in case the peace mission turns into war-fighting, (which happens, although very rarely), and, at the same time, they have to achieve the goals of their missions with the minimal use of force, if not completely without the resort to arms.

The theatre for peace operations differs in important ways from the classical military front. Although soldiers are deployed in military formations, their mandate is fully different (with some exceptions) ${ }^{2}$ from what they learned during their basic military training. Their police-like activities push them into the role of negotiator, intelligence gatherer, mediator, observer, listener, humanitarian worker, helper, and social worker. It is questionable to what extent they still need the heroism, high fighting morale, or developed will to fight that basic military training strives to inculcate. Gabriel argued that modern war-fighting activities put soldiers into stressful situations, with a resulting

* Ljubica Jelusic is Professor of Defense Studies at the University of Ljubljana, Slovenia. The data in the paper belong to the research projects "Slovenian Military in Peace Operations" and "Slovenian Police in Peace Operations," conducted by the Defense Research Center, Institute of Social Sciences, Faculty of Social Sciences, University of Ljubljana, Slovenia, $2002-2005$. An earlier version of this paper was presented at the International ISA RC01 Armed Forces and Conflict Resolution International Conference, Ankara, Turkey, 6-9 July 2004.

1 Some militaries are deployed without weapons as a show of their neutrality. For example, Swiss soldiers were deployed in the KFOR mission as unarmed military persons, due to Switzerland's decision to stay fully neutral in the conflict. After significant public debate, the citizens decided in a referendum in 2002 that Swiss soldiers are allowed to carry weapons in peace operations.

2 In peace enforcement operations, soldiers are expected to act in a militarily robust manner. 
high number of psychological losses, which is evidence of the "no more heroes" tenor of the current mode of combat. ${ }^{3}$ In peace operations, there is even greater doubt about the necessity for heroes, and more moderate and neutral soldiers are more in demand. Therefore if, in combat missions, soldiers have to maintain a high level of morale, which helps them to fight eagerly in order to win the battle, in peace operations they have to be motivated to act with the minimal use of force, but with substantial mental and psychological strength. "Heroes without the power of arms" would be the most appropriate description of the soldiers regarded as traditional peacekeepers or "what it has generally meant to be a peacekeeper in 1990s.",

The famous peace activist and researcher Anatol Rapoport once said that, if we take the arms from the soldier, he is nothing. In peace operations, the soldiers (and policemen) have to fulfill their entire mandates without the extensive use of force. However, in many post-Cold War peace operations, the peacekeepers have adopted the "warrior for peace" mentality, derived from their deployment under extremely tense circumstances, especially in times of tenuous peace in the wake of civil war.

\section{Motivation to Join Peace Operations}

There are many different motives that shape the decisions of soldiers or policemen to join peacekeeping missions. In contemporary all-volunteer forces, some soldiers join the military specifically because they would like to serve in peace operations. ${ }^{5}$ Participation in different peace operations constitutes an important part of the military curriculum vitae. Some militaries deploy peacekeepers on a voluntary basis, which means that active soldiers - and reserve soldiers, too-may voluntarily apply for peacekeeping missions outside the country, whereas in some other armies soldiers are ordered to duty with peacekeeping units. In both cases, the soldiers need some intrinsic and extrinsic driving forces to help them make the decision to join the peacekeeping force, or to convince him/her of the positive outcomes of the mission.

\section{Daily Experiences, Stress, and Motivation}

Once deployed in the field, the soldiers - and, similarly, policemen - have to develop other motives in order to maintain their readiness to carry out their mission to completion. Usually, after the first month-which is always very busy, filled with learning new jobs and new social networks - the sobering effect of peace missions takes place. Immersed in the reality of a peacekeeping operation, soldiers are forced to realize the

3 Richard A. Gabriel, Nema vise heroja (Zagreb: ALFA, 1991: 149-50; translation of No more Heroes. Madness and Psychiatry in War, 1987).

4 Eva Johansson, The Unknown Soldier: A Portrait of the Swedish Peacekeeper at the Threshold of the $21^{\text {st }}$ Century (Karlstad: Karlstad University Studies, 2001): 61.

5 As was noticed among Slovenian volunteers, who entered the Slovenian Army in 2003, having been attracted by the media's presentation of the military's peacekeeping activities. The official Slovenian military campaign to attract young boys and girls to become soldiers, activated in 2004, is essentially based on propagating the peacekeeping tasks of the Slovenian Army. 
difference between their personal image of the mission and the praxis of the task at hand. ${ }^{6}$ In comparison with military peacekeeping, the practice of police peacekeeping differs in some particulars. The term of deployment is longer, usually one year, with the possible prolongation of half a year. In addition, these servicemen live among the local population, and perforce must learn a great deal about the habits and attitudes of the locals. Their motivation must be sufficient and consistent enough to survive the long absence from family and home. The stressors are similar to those in the military framework, but with a higher impact of the local population's attitudes and behavior than in the military.

Researchers who have surveyed the stress factors in peace operations distinguish between pre-deployment, early deployment, and late deployment stressors. ${ }^{7}$ Why do we have to elaborate on stressors, given that our focus here is on motivation? The explanation would be that the same factors that serve as generators of high levels of motivation among peacekeepers might serve as stressors as well. For example, if a soldier's family has supportive attitudes towards the mission, this may motivate the soldier to join and expect positive outcomes of the mission. On the other hand, family concerns may push the soldier into isolation and other typical occupational stresses.

Ulrich von Hagen has written that peacekeeping deployment and duty could be considered an important part of the modern concept of occupational stress in the military. $^{8}$ The peacekeepers experience separation from home, family, and garrison life; they feel isolated due to the remote locations, obstacles to communication, newly configured units, cross-attached individuals, and family concerns. A high degree of ambiguity growing out of unclear missions and confusion in command structures, roles, and identity has been detected as the second important dimension of stress. It often results in feelings of powerlessness, boredom, and the sense of threat and danger. ${ }^{9}$ Segal and Segal have explained this boredom as the consequence of contradictory tasks; soldiers who have been trained to close with, engage, and defeat an enemy often have difficulty

6 In the Slovenian survey among peacekeepers, we recognized that even veterans in peacekeeping, those who joined the missions two or more times, are still subjected to disappointment, while passing the initial stage of the mission.

7 T. Paul Bartone, Amy B. Adler, and Mark A. Vaitkus, "Dimensions of Psychological Stress in Peacekeeping Operations," Military Medicine 163 (1998): 590 - 1.

8 Ulrich von Hagen, "Stress and Stress Management in the Military," in Armed Forces and International Security, Global Trends and Issues, eds. Jean Callaghan and Franz Kernic (Münster: LIT, 2003), 258.

9 Bartone, et al, "Dimensions of Psychological Stress," 591. 
adapting to a mission of observing, verifying, and reporting. ${ }^{10}$ The cognitive inconsistence between the soldiers' perception of the peace mission and understanding of the mandate on the one hand, and the reality of daily work on the other, leads into identity crisis and tensions. ${ }^{11}$

\section{Factors that Influence Motivation}

Fabrizio Battistelli has elaborated the typology of soldiers' motivation to join missions, employing empirical data and utilizing current social science phraseology, using premodern, modern, and post-modern terms. He argues that some soldiers join peacekeeping missions due to their primarily pre-modern motives, such as "to be useful to others" or "to strengthen the country's image at the international level." Another group of soldiers espoused modern motives, like "to earn some extra money, to learn things that could be useful to one's career or on one's return to civilian life." The third group is driven by postmodern motives, such as "to satisfy a desire for adventure" or "to have a meaningful personal experience." $" 12$ In most empirical surveys among peacekeepers, we would find all the above-mentioned motives, but the importance of them would vary from soldier to soldier, depending also on when the survey was conducted - in the pre-deployment, mid-deployment, or post-deployment phase.

Giuseppe Caforio made a survey among one hundred Italian peacekeepers in UNOSOM (United Nations Mission in Somalia), which was among the first empirical tests of post-Cold War peacekeeping operations' motivation (conducted in May 1993). His findings on motivation in the pre-deployment phase have shown the overwhelming spirit of adventure, escape from home routine, and expectations of something new as basic motives to join. Additionally, the soldiers had some values of altruistic military culture, while expecting to help and do something important in their life. The economic reward was the third most important motive for participating in the mission. ${ }^{13}$

Among the current attempts in the field of military sociology to define the components of the motivation for peace missions there are at least three different research

10 David R. and Mady Wechsler Segal, Peacekeepers and their Wives. American Participation in the Multinational Force and Observers (Westport, CT: Greenwood Press, 1993), 37. Slovenian soldiers, deployed in SFOR, in Bosnia and Herzegovina, used to complain in surveys on peacekeeping (Jelusic et al, 2004), that they were trained for combat missions - that they are combatants - but that nothing in the mission looked like a combat theatre. See Ljubica Jelusic and Maja Garb, "Job Satisfaction and Motivation for Peace Support Operations among Slovenian Soldiers and Policemen," Paper presented at the International ISA RC01 Armed Forces and Conflict Resolution International Conference, Ankara, Turkey, 6-9 July 2004.

11 Volker C. Franke, "Resolving Identity Tensions: The Case of the Peacekeeper," Journal of Conflict Studies 19 (1999): 129.

12 Fabrizio Battistelli, "Peacekeeping and the Postmodern Soldier," Armed Forces and Society 23:3 (1997): 467-84.

13 Giuseppe Caforio, "Militärische UN-Einsätze: Italienische Erfahrungen," in Friedensengel im Kampfanzug? Zu Theorie und Praxis militärischer UN-Einsätze, ed. Georg-Maria Meyer (Opladen: Westdeutscher Verlag, 1996). 
projects under way in Europe, conducted among Swiss, German, and Slovenian soldiers deployed in the peace missions SFOR and KFOR in the Balkans. ${ }^{14}$ Although the surveys are not based on a common research model and methodology, and the researchers were driven by their own countries' interests in gaining knowledge about the soldiers' motivation, they have had very similar ideas on how to measure the motivation of peacekeepers. They have deduced numerous similar factors of peacekeepers' motivation from the answers given by the respondents. The main differences are in the relative importance of motivating factors in different units. Moreover, the researchers who surveyed the dimensions of psychological stress in peacekeeping or stress in the daily experiences of peacekeepers have conducted their surveys on similar variables and indicators. ${ }^{15}$

\section{Slovenian Peacekeepers and their Motivation}

Researchers at the Defense Research Center in the Faculty of Social Sciences at the University of Ljubljana are conducting a survey among Slovenian contingents deployed with SFOR in Bosnia and Herzegovina. The survey began in 2002, and will end in 2005. The Slovenian contingents (SICON) in the Multinational Battle Group (MNBG) are deployed in the area of Doboj. The Slovenian contingents in the Multinational Specialized Unit (SICON MSU) are stationed in Sarajevo, but are deployed on tasks throughout the entire country. The surveys are three-point measurements: before assignment, during assignment, and after assignment. The first two measurements are conducted using a semi-standardized questionnaire (self-administered), and the last measurement after assignment is conducted by face-to-face semi-structured interviews. The survey is a trend survey in contingents SICON MNBG I, II, III, IV (deployed with SFOR between January 2003 and December 2004) and SICON MSU IX, X, XI (deployed with SFOR between April 2003 and October 2004). The results of the survey should help Slovenian military officials to recognize problems of soldiers' motivation, identify potential actions that can be taken by the military to change the level of motivation, and sources of increasing job satisfaction in the Slovenian all-volunteer forces.

${ }^{14}$ For the Swiss case, see Jonathan Bennett, Rolf P. Boesch, and Karl W. Haltiner, "Swisscoy Motivation und Einsatzzufriedenheit," Allgemeine Schweizerische Militärzeitschrift 169:3 (2003): 20-22. For the German case, see Heiko Biehl and Reinhard Mackewitsch, "How German Soldiers Cope with the Peacekeeping Operation in Kosovo," paper presented at XV World Congress of Sociology, RC 01 Armed Forces and Society, "Session 7: Peacekeeping," Brisbane, Australia, July 2002; and Maren Tomforde and Jörg Keller, "Who Wants to Go Again? Motivation of German Soldiers for and during Peacekeeping Missions," paper presented at the international ISA RC01 Armed Forces and Conflict Resolution International Conference, Ankara, Turkey, 6-9 July 2004. For the Slovenian case, see Jelusic and Garb, "Job Satisfaction and Motivation for Peace Support Operations"; and Ljubica Jelusic, Vinko Vegic, Maja Garb, and Jelena Trifunovic, "Slovenska vojska v mirovnih operacijah: Cilji in rezultati prve faze empirisnega raziskovanja (Slovenian Army in the Peace Operations: Aims and Results of the First Phase in the Empirical Research)," Slovenska vojska 12:5 (12 March 2004): 1-15.

15 Bartone, et al., "Dimensions of Psychological Stress" and Johansson, The Unknown Soldier. 
The military needs these answers urgently because of the expected problems in recruiting peacekeepers in the near future. In the period between 1997 and 2003, there were approximately 1200 individual missions fulfilled by soldiers of the Slovenian Army as part of peacekeeping operations. That means that more than every sixth soldier (in a military of 6500 servicemen and servicewomen) was already deployed on peacekeeping missions abroad.

The researchers at the Defense Research Center measure the influences of different factors (the soldiers' home environment, mission external environment, mission internal environment, and personal cognitive identity with the mission) on his or her assignment motivation. The variables that shape the peacekeepers' home environment are support from the family and friends, support of public opinion, media, and politicians. The variables that define the mission external environment are threats and dangers in the area of the mission, local population, and multinational military units. The mission internal environment is defined by the vertical and horizontal cohesion in the deployed military unit, its quality of preparation for the mission, equipment, logistics, infrastructure, and organization of free time. The personal cognitive identity with the mission deals with the level of trust the peacekeepers have in the aims and success prospects of the mission, material advantages, and usefulness of the experience for their future military career.

The survey in two Slovenian military contingents, deployed in SFOR between January and July 2003 (SICON MNBG I) and between April and October 2003 (SICON MSU IX), has shown some differences between servicemen in MSU-who are military policemen, on average in their mid-thirties - and the servicemen in MNBG, who are on average twenty-seven years old. Although they are members of the same army, their personal expectations of and motives for participating in a peacekeeping mission vary. In the pre-deployment stage, the younger and mostly unmarried MNBG participants (in order of importance) expected to be met with an attractive job with many new military experiences, to contribute to the image of Slovenia in the world, to be able to put their military knowledge to good use, to achieve some economic reward, to provide help to the local population, and to gain knowledge of the people and culture of Bosnia-Herzegovina. In the late deployment phase, the order of these motives changes. The soldiers confirmed the gaining of new knowledge about the country and culture, contributing to the image of Slovenia, earning additional money, gaining new military experiences, helping the local population, and-far down at the end-usefully deploying their military knowledge. The results show the difference between expectations and the fulfillment of them. The anticipated combat-like situation did not happen, but they have learned some new military skills, and they gained insight into the country's changes in the past decade.

The MSU contingent of older and mostly married servicemen with children had more rational expectations. First of all, they were motivated by the economic reward, by contributing to the image of Slovenia, and by gaining new military knowledge. They did not expect to be of particular help to the local population. They confirmed these expectations in the late-deployment phase, with the exception of gaining new military knowledge, which they reported as not having been achieved (results are from the sur- 
vey database "Slovenian Army in Peace Operations," published in Jelusic, et al, "Slovenska vojska v mirovnih operacijah").

The mission external environment was more important to higher self-respect on the part of the Slovenian soldiers in late-deployment phase than in the beginning. The expected threats to be coped with were "civilian" threats and the remnants of past military activities, such as mine fields. The life in the multinational unit was interesting, and relations with other participants of the mission were good. The servicemen expected and enjoyed respect from other servicemen; some reported encountering more professional and respectful behavior from other officers than from their own. Although they did not expect troubles in communication with the local citizens (Slovenian soldiers still speak some Serbo-Croatian), they were surprised by the warm acceptance and openness of the citizens. The local citizens seemed to be more pleasant when they realized that the troops in their midst were from the "former Yugoslavia." The level of importance of these factors was high, and stayed stable over the duration of mission.

The "home front" of the peacekeepers contained some contradictions for the motivation to serve in the mission. While family and friends supported the peacekeepers before and during the mission, the Slovenian media and the political elite were perceived as being not fully supportive of the mission, and of the peacekeeping task of the Slovenian Army in general. The soldiers are convinced that the media generate negative images of the armed forces in Slovenian society. During their long absence from home, this conviction was reinforced. The pre-deployment stereotype gained strength after every small critical media observation.

The mission internal military environment was the social microcosm of the peacekeepers. Life with comrades changed from eight-hour daily shifts at work at home to living together around the clock. In the late deployment phase, people perceived this close relation as a heavy emotional strain, one for which they were not prepared. The trust they placed in their leaders was high in the pre-deployment phase, but decreased significantly during the mission. They also criticized the preparation for the mission, saying that they received enough (too much, according to some) military training, but lacked specific education on the political and social situation in Bosnia-Herzegovina, as well as anthropological knowledge, English refresher courses, and skills in managing the stress of separation from their families.

Three basic environments have high influence on the motivation of the peacekeepers and their personal identity, but the discrepancy between their expectations to be deployed in traditional military tasks and the reality of the police-like mission seems to have the highest impact. Therefore, the unfulfilled attractiveness of the peacekeeping job (although it pays well) and the lack of proper training for mission tasks have a significant influence on decreasing motivation, which seems to continue in the post-deployment phase for Slovenian soldiers. ${ }^{16}$ Disappointment does not seem to have a substantial influence on soldiers' preparedness to join another mission. Soldiers with whom we had a group discussion on the survey findings after four months of home rehabilitation have said that they would like to go again-to every mission, except

16 Jelusic, et al., "Slovenska vojska v mirovnih operacijah." 
SFOR. It seems that military adventurism (a post-modern motive) increases in importance in attracting soldiers for the second (or more) term(s).

\section{Conclusion}

In conclusion, we may observe that the pre-deployment motivation of all surveyed peacekeepers has one variable in common: the perceived attractiveness of the expected job, offering adventure and new military experiences. The reality of the mission lowers these post-modern expectations and replaces them with the objectives of economic reward.

If application for peacekeeping missions were on volunteer basis for all personnel, it would be possible to conclude that different operations with different mandates attract different kind of personalities to apply. Stable, not dangerous, low-intensity missions are attractive for soldiers' first deployments, while more risky, long-distance missions attract peacekeeping veterans. When deployed, the support from the home environment, external mission environment, and internal mission environment must help servicemen to keep a stable level of motivation to work efficiently over the entire term. The impact of different motivating factors varies from country to country, and usually represents the special social circumstances of the peacekeepers' donor country. The factors that motivate the soldiers and policemen may also help create stressful conditions. If we turn back to Battistelli's typology of motivations to join these missions, we should, on the basis of current surveys, conclude that, in the pre-deployment phase, peacekeepers are guided by pre-modern motives (help those who need us, contribute to the country's image) and post-modern motives (attractiveness of the job). Over the course of the mission, the post-modern motives diminish in influence, and modern motives (economic reward, military experience) become more influential. The Slovenian policemen - veterans of peacekeeping missions in Bosnia-Herzegovina, Kosovo, and East Timor-have a specific philosophy in this regard: usually they say that the economic rewards are important driving forces, but to survive a year or more in the mission, peacekeepers must develop some other, mostly post-modern motives. 


\section{Bibliography}

Battistelli, Fabrizio. "Peacekeeping and the Postmodern Soldier." Armed Forces and Society 23, no. 2 (1997).

Franke, Volker C.. "Resolving Identity Tensions: The Case of the Peacekeeper." Journal of Conflict Studies (1999).

Gabriel, Richard A.. Nema vise heroja. Zagreb: ALFA,, 1991.

Johansson, Eva. The Unknown Soldier: A Portrait of the Swedish Peacekeeper at the Threshold of the 21st Century. Karlstad: Karlstad University Studies, 2001.

T. Bartone, Paul, Amy B. Adler, and Mark A. Vaitkus. "Dimensions of Psychological Stress in Peacekeeping Operations ." Military Medicine (1998).

von Hagen, Ulrich. "Stress and Stress Management in the Military." In Armed Forces and International Security, Global Trends and Issues. Vol. 258. Münster: LIT, 2003. 